\title{
Sacroiliac joint motion in patients with degenerative lumbar spine disorders
}

\author{
Yukitaka Nagamoto, MD, PhD, ${ }^{1}$ Motoki Iwasaki, MD, PhD, ${ }^{2}$ Hironobu Sakaura, MD, PhD, ${ }^{3}$ \\ Tsuyoshi Sugiura, MD, PhD, ${ }^{1}$ Takahito Fujimori, MD, PhD, ${ }^{4}$ Yohei Matsuo, MD, ${ }^{1}$ \\ Masafumi Kashii, MD, PhD, ${ }^{1}$ Tsuyoshi Murase, MD, PhD, ${ }^{1}$ Hideki Yoshikawa, MD, PhD, ${ }^{1}$ and \\ Kazuomi Sugamoto, MD, PhD'
}

1Department of Orthopaedics, Osaka University Graduate School of Medicine, Osaka; '2Department of Orthopaedic Surgery, Osaka Rosai Hospital, Osaka; ${ }^{2}$ Department of Orthopaedic Surgery, Kansai Rosai Hospital, Hyogo; and ${ }^{4}$ Department of Orthopaedic Surgery, Sumitomo Hospital, Osaka, Japan

\begin{abstract}
OBJECT Usually additional anchors into the ilium are necessary in long fusion to the sacrum for degenerative lumbar spine disorders (DLSDs), especially for adult spine deformity. Although the use of anchors is becoming quite common, surgeons must always keep in mind that the sacroiliac (SI) joint is mobile and they should be aware of the kinematic properties of the SI joint in patients with DLSDs, including adult spinal deformity. No previous study has clarified in vivo kinematic changes in the SI joint with respect to patient age, sex, or parturition status or the presence of DLSDs. The authors conducted a study to clarify the mobility and kinematic characteristics of the SI joint in patients with DLSDs in comparison with healthy volunteers by using in vivo 3D motion analysis with voxel-based registration, a highly accurate, noninvasive method.
\end{abstract}

METHODS Thirteen healthy volunteers (the control group) and 20 patients with DLSDs (the DLSD group) underwent low-dose 3D CT of the lumbar spine and pelvis in 3 positions (neutral, maximal trunk flexion, and maximal trunk extension). SI joint motion was calculated by computer processing of the CT images (voxel-based registration). 3D motion of the SI joint was expressed as both $6 \mathrm{df}$ by Euler angles and translations on the coordinate system and a helical axis of rotation. The correlation between joint motion and the cross-sectional area of the trunk muscles was also investigated.

RESULTS SI joint motion during trunk flexion-extension was minute in healthy volunteers. The mean rotation angles during trunk flexion were $0.07^{\circ}$ around the $x$ axis, $-0.02^{\circ}$ around the $y$ axis, and $0.16^{\circ}$ around the $z$ axis. The mean rotation angles during trunk extension were $0.38^{\circ}$ around the $x$ axis, $-0.08^{\circ}$ around the $y$ axis, and $0.08^{\circ}$ around the $z$ axis. During trunk flexion-extension, the largest amount of motion occurred around the $x$ axis. In patients with DLSDs, the mean rotation angles during trunk flexion were $0.57^{\circ}$ around the $x$ axis, $0.01^{\circ}$ around the $y$ axis, and $0.19^{\circ}$ around the $z$ axis. The mean rotation angles during trunk extension were $0.68^{\circ}$ around the $x$ axis, $-0.11^{\circ}$ around the $y$ axis, and $0.05^{\circ}$ around the $z$ axis. Joint motion in patients with DLSDs was significantly greater, with greater individual difference, than in healthy volunteers. Among patients with DLSDs, women had significantly more motion than men did during trunk extension. SI joint motion was significantly negatively correlated with the cross-sectional area of the trunk muscles during both flexion and extension of the trunk.

CONCLUSIONS The authors elucidated the mobility and kinematic characteristics of the SI joint in patients with DLSDs compared with healthy volunteers for the first time. This information is useful for spine surgeons because of the recent increase in spinopelvic fusion for the treatment of DLSDs.

http://thejns.org/doi/abs/10.3171/2014.12.SPINE14590

KEY WORDS sacroiliac joint; 3D kinematics; degenerative lumbar spine disorders; sacral

ABBREVIATIONS DLSD = degenerative lumbar spine disorder; ICC = intraclass correlation coefficient; RMSE = root mean square error; RSA = roentgen stereophotogrammetric analysis; $\mathrm{SI}=$ sacroiliac

SUBMITTED June 14, 2014. ACCEPTED December 12, 2014

INCLUDE WHEN CITING Published online May 15, 2015; DOI: 10.3171/2014.12.SPINE14590.

DISCLOSURE This work was supported by a grant-in-aid for Scientific Research C (KAKENHI:22591632) from the Ministry of Education, Culture, Sports and Technology, Japan. 
$\mathrm{U}$ SUALLY additional anchors into the ilium are necessary in long spine fusion to the sacrum for degenerative lumbar spine disorders (DLSDs), especially adult spine deformity. Many fixation techniques are available. The 2 most commonly used are iliac screws and the S-2 alar iliac method. Although the use of anchors is becoming quite common, surgeons must always keep in mind that the sacroiliac (SI) joint is mobile, and they should be aware of the kinematic properties of the SI joint in patients with DLSDs, including adult spinal deformity.

Different techniques have been used to quantify the mobility of SI joints. ${ }^{4,13,17-19,25}$ Among them, roentgen stereophotogrammetric analysis (RSA) has been viewed as the gold standard for evaluating 3D micromotion in joints. With RSA, a maximum rotation of $3.9^{\circ}$ around a single axis has been measured, and the translation along that axis does not exceed $2 \mathrm{~mm}$ in the SI joint. ${ }^{17-19}$ No previous study, however, has successfully clarified in vivo kinematic change with respect to patient age, sex, or parturition status or the presence of DLSDs, yet several researchers have speculated that SI joint motion generally decreases with aging and increases during the perinatal period., ${ }^{2,23}$ Therefore, it is very important to clarify the kinematic property of the SI joint in patients with DLSDs.

We have developed a motion analysis system to evaluate in vivo 3D kinematics of the spine and have already used it to report accurate kinematics of the spine, including kinematics in pathological conditions. ${ }^{5-8,10-12,15}$ The purpose of the study we report here is to clarify the mobility and kinematic characteristics of the SI joint in patients with DLSDs compared with healthy volunteers using in vivo $3 \mathrm{D}$ motion analysis using voxel-based registration, a highly accurate, noninvasive method.

\section{Methods}

Study participants consisted of 13 healthy volunteers (control group: 13 men; mean age 30.0 years, age range 19-37 years) and 20 participants with degenerative lumbar spine disorders (DLSD group: 10 men, 10 women; mean age 63.1 years, age range $41-80$ years). In the control group, no volunteers had low-back pain; none had referred pain from the SI joint in the buttock, groin, or lower extremity; and none had any medical history of SI joint disorder. In the DLSD group, all patients underwent spine surgery because of DLSDs. The diagnoses were as follows: 11 patients with degenerative spondylolisthesis of L-4, 1 patient with isthmic spondylolisthesis of L-4, 4 patients with lumbar canal stenosis of L4-5 due to degeneration and hypertrophy of the ligamentum flavum, 2 patients with lumbar canal stenosis of L5-S1 due to degeneration and hypertrophy of the ligamentum flavum, 1 patient with multilevel lumbar canal stenosis from L-2 to L-5 due to degeneration and hypertrophy of the ligamentum flavum, and 1 patient with lumbar canal stenosis of L4-5 due to osteoporotic vertebral collapse of L-4. In the DLSD group, all individuals had some clinical symptom in the lower extremities and/or the low back, but none showed SI joint pain during provocation tests. The institutional review board of Osaka University approved all study protocols in advance, and all participants provided written confirmation of fully informed consent.

\section{Acquisition of 3D CT Images}

All 33 participants underwent CT scanning of the entire lumbar spine and entire pelvis by a multidetector-row helical CT scanner (LightSpeed VCT, GE Healthcare). The scans were obtained in 3 positions, including neutral, maximal trunk flexion, and maximal trunk extension positions. Supportive devices were used to maintain the test positions (Fig. 1). For the neutral position, the participants lay supine on the CT table. Maximal trunk flexion was the maximal active flexion. We instructed participants to arch their back as much as possible on the CT table. During scanning, supportive devices kept the back in position. Maximal trunk extension was also maximal active extension. We instruct-

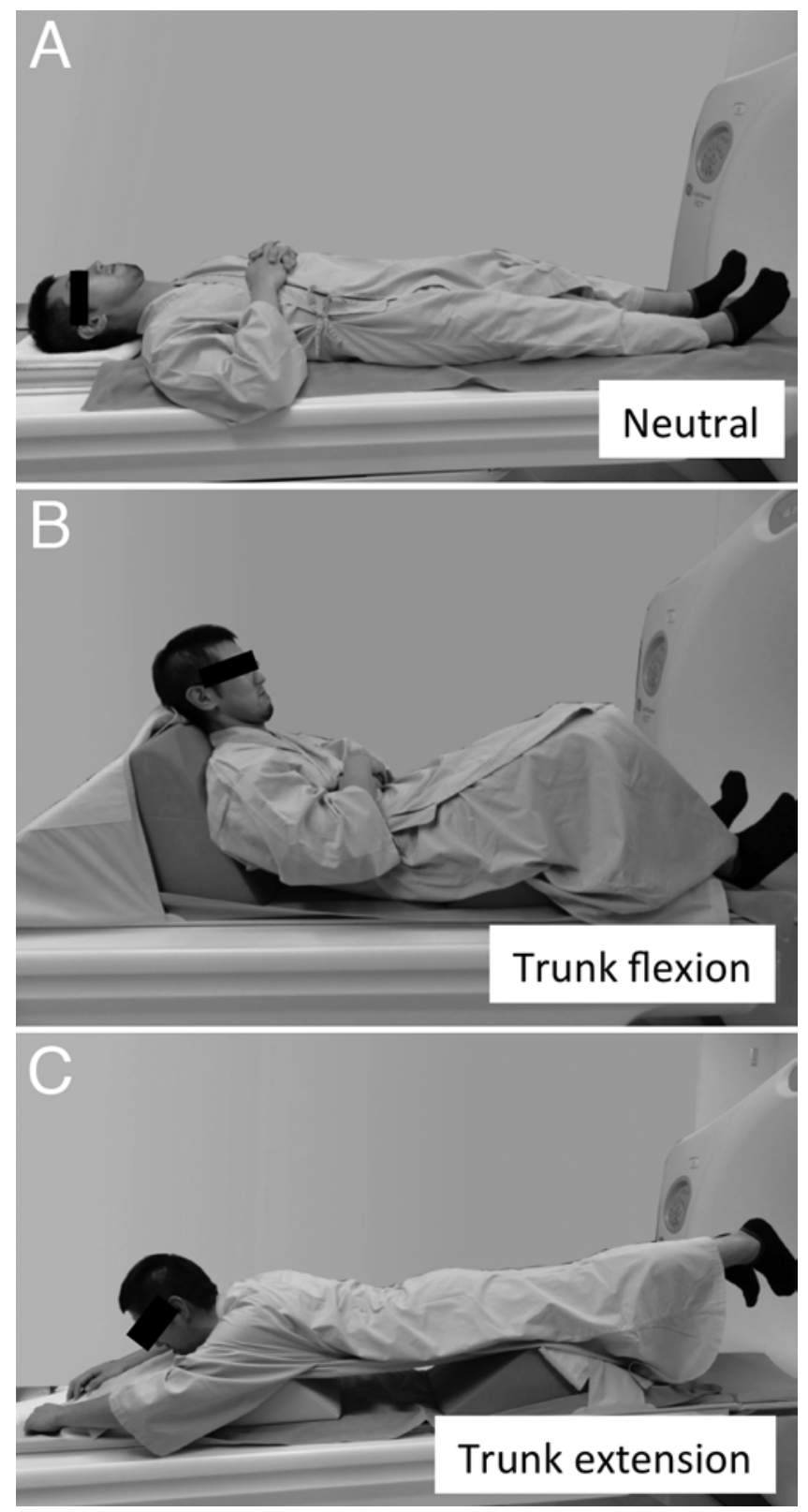

FIG. 1. Scans were obtained in 3 positions. In trunk flexion and extension, dedicated supportive devices were used to help study participants maintain their position. 
ed participants to make their abdomen protrude as much as possible while lying on the supportive devices. The CT slice thickness was $0.625 \mathrm{~mm}$, and the tube voltage was $120 \mathrm{kV}$. The tube current was reduced to $50 \mathrm{~mA}$ in the neutral position and to $20 \mathrm{~mA}$ in the other positions to reduce $\mathrm{x}$-ray exposure. The estimated x-ray exposure was 267.2 dose-length products (DLPs) and was less than that specified by the routine CT protocol for lumbar spine imaging at Osaka University Hospital. Scanning data were saved in DICOM format and transmitted to a computer workstation, where image processing was performed using the software VirtualPlace (M series, Medical Imaging Laboratory).

\section{Motion Analysis}

The method for motion analysis has been fully described elsewhere, with segmentation occurring first. ${ }^{5,10-12,15}$ The bilateral ilia and sacrum were semiautomatically extracted from the images using the CT threshold for bone (150 HU). $3 \mathrm{D}$ migration of each bone was measured next. These segmented bones in the neutral position were superimposed in the other positions using the voxel-based registration method. The 3D migration of each bone was expressed as a matrix. Then the relative motion of the sacrum with respect to the ilium was calculated on the anatomical orthogonal coordinate system of the $\operatorname{sacrum}^{18}$ (Fig. 2) using original software (Orthopedic Viewer, Osaka University) developed in previous research on spine kinematics. This was expressed in $6 \mathrm{df}$ by Euler angles with the sequence of pitch $(\mathrm{X})$, yaw (Y), roll (Z), and translations. All SI joint motion was expressed as right SI joint motion. Left SI joint motion was transformed into mirror motion across the Y-Z plane by inverting the sign of rotation around the $y$ axis, rotation around the $\mathrm{z}$ axis, and translation along the $\mathrm{x}$ axis to evaluate them as right SI joint motion. The SI joint motion can be visualized with 3D animations (Videos 1 and 2).

VIDEO 1. A healthy study participant. Sacroiliac joint motion was minute and mainly occurred around the joint surface (the $x$ axis). Copyright Yukitaka Nagamoto. Published with permission. Click here to view with Media Player. Click here to view with Quicktime.

VIDEO 2. An illustrative case from the group with degenerative lumbar spine disorders (the DLSD group). Sacroiliac joint motion was considerably increased in comparison with motion in healthy volunteers. Copyright Yukitaka Nagamoto. Published with permission. Click here to view with Media Player. Click here to view with Quicktime.

In addition, a helical axis and the rotation angle around the axis were calculated to evaluate SI joint mobility as a single value. The helical axis is a unique axis in space that completely defines 3D motion of a rigid body from Position 1 to Position 2. It is analogous to the instantaneous axis of rotation for plane motion.

\section{Accuracy Validation of the Voxel-Based Registration Method}

We newly validated the accuracy of the voxel-based registration method for the SI joint with CT imaging of a fresh-frozen pelvis of a laboratory pig. The sacrum and right ilium were taken out of the entire spine and at least 8 tantalum bone markers with a radius of $1.0 \mathrm{~mm}$ were implanted into each bone, using a device containing a hollow

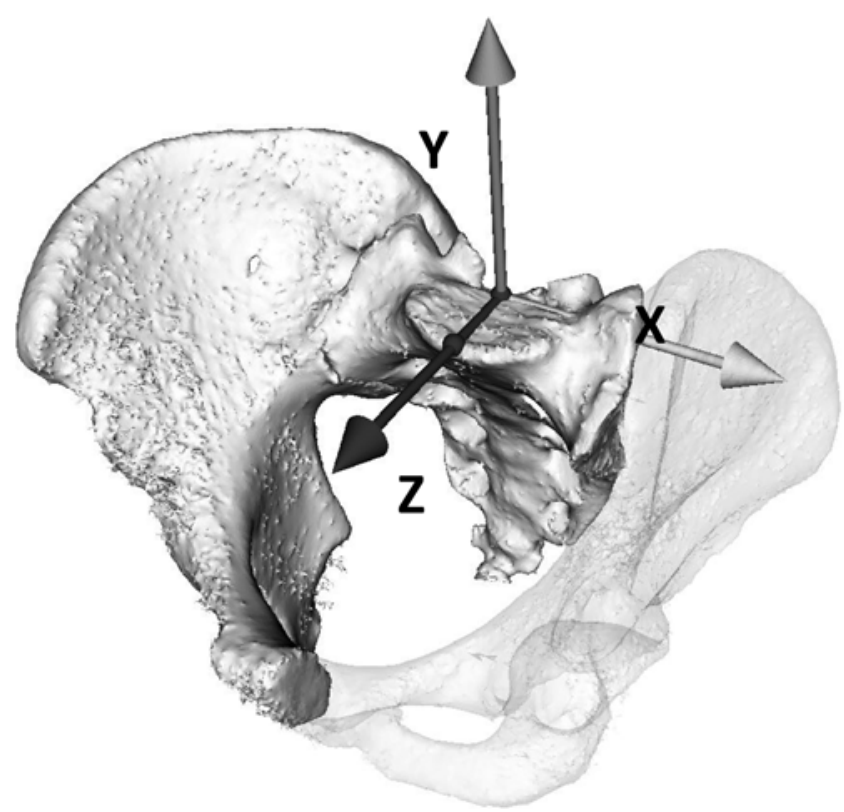

FIG. 2. Anatomical orthogonal coordinate system. The origin is located at the posterior border of the endplate of the sacrum in the midsagittal plane. The $z$ axis is defined as the line connecting the anterior and posterior borders of the endplate of the sacrum, with the anterior direction representing positive values. The y axis is defined as being perpendicular to the $z$ axis, with the superior direction representing positive values. The positive $x$ axis is directed to the left.

needle with a spring-loaded piston. Subsequently, using the same scanning parameters as in humans, we obtained 9 CT scans in the following order: neutral, moderate and extreme internal/external rotation, and moderate and extreme flexion-extension of the SI joint. After segmentation, the segmented bones in the neutral position were superimposed on the other 8 positions by using voxel-based registration. The true value of each migration was obtained with marker-based registration as a baseline. Accuracy was defined as the proximity of measurements to the true value. The root mean square distance was calculated in $\mathrm{Rx}$ (flexion-extension), Ry (axial rotation), Rz (lateral bending), Tx (lateral translation), Ty (superoinferior translation), and $\mathrm{Tz}$ (anteroposterior translation) for assessment of accuracy. The accuracy was $0.00^{\circ}$ in $\mathrm{Rx}, 0.11^{\circ}$ in $\mathrm{Ry}, 0.03^{\circ}$ in $\mathrm{Rz}, 0.01 \mathrm{~mm}$ in Tx, $0.12 \mathrm{~mm}$ in Ty, and $0.09 \mathrm{~mm}$ in Tz.

\section{Measurement of the Cross-Sectional Area of the Trunk Muscles}

The cross-sectional area of the trunk muscles was also measured using CT to investigate the correlation between the SI joint motion and the cross-sectional area. First, axial images of the trunk muscles were obtained at the tip of iliac crest and both below and above the 10th slice of the level. Second, the trunk muscles, including both sides of the rectus abdominis, the oblique abdominis, the transverse abdominis, the psoas major, and the erector spinae, were segmented manually on each image (Fig. 3). Third, the muscle area was extracted within the segmented area according to muscle density $(10-80 \mathrm{HU})$ on each image. Finally, the cross-sectional area $\left(\mathrm{cm}^{2}\right)$ was calculated by 


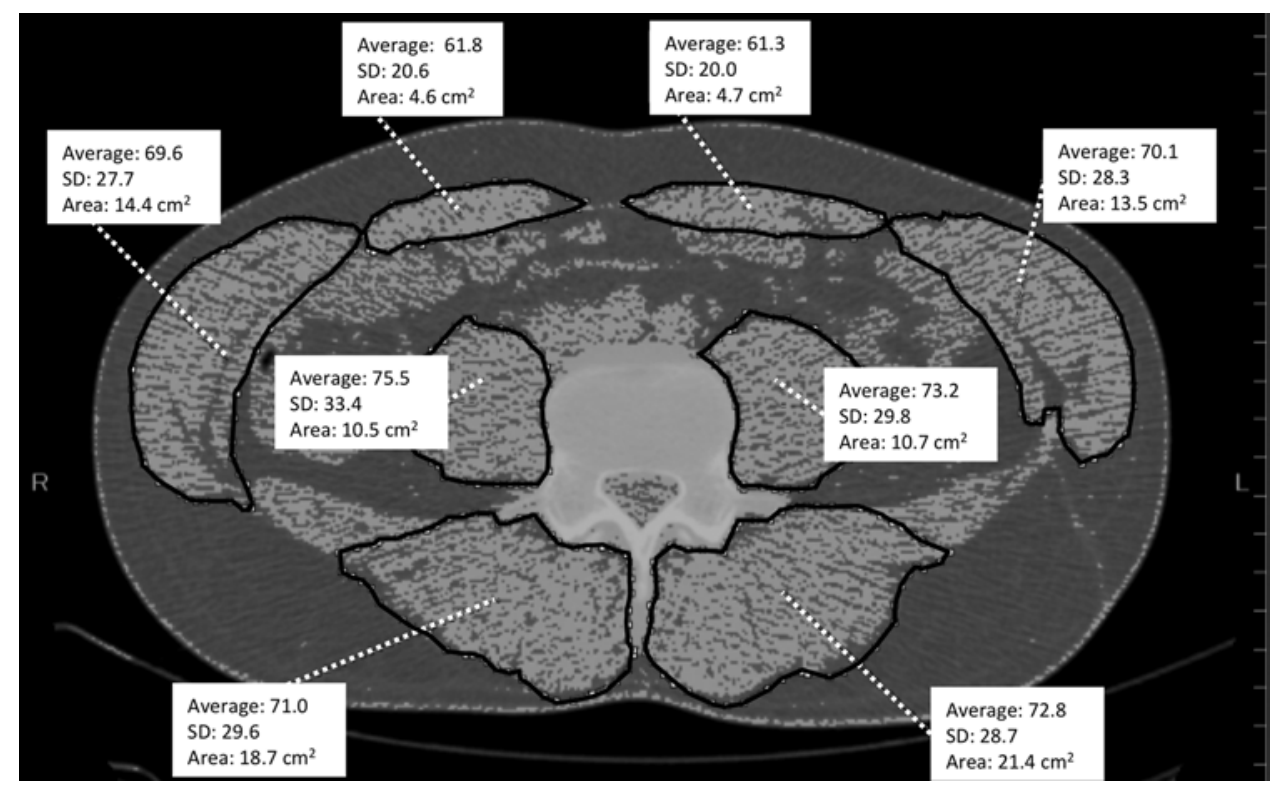

FIG. 3. The cross-sectional area of the trunk muscles. Measurement was performed using computer software. Values presented with SD are in Hounsfield units.

averaging the sum of the muscle area of the 3 images. All procedures were performed using the software VirtualPlace (M series). To assess measurement reproducibility, 2 authors independently calculated the cross-sectional area
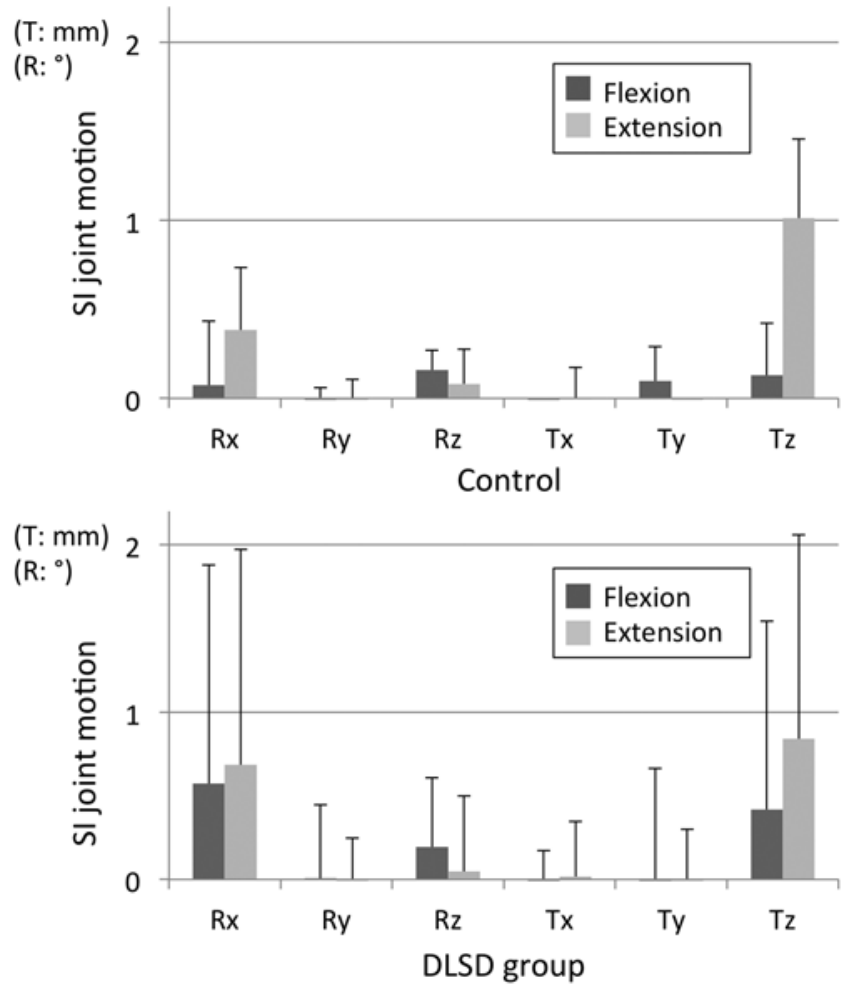

FIG. 4. Motion of the sacrum relative to the ilium (SI joint motion) described with 6 df by rigid body Euler angles and translations using the anatomical orthogonal coordinate system. Data represent mean $\pm \mathrm{SD}$. $\mathrm{R}=$ rotation; $\mathrm{Rx}=$ flexion-extension; $\mathrm{Ry}=$ axial rotation; $\mathrm{Rz}=$ lateral bending; $\mathrm{T}=$ translation; $\mathrm{Tx}=$ lateral translation; $\mathrm{Ty}=$ superior translation; $T z=$ anterior translation. of the trunk muscles for 10 volunteers in the control group twice, with 1 week elapsing between each measurement. The intraobserver and interobserver intraclass correlation coefficient (ICC) and root mean square error (RMSE) were assessed. For intraobserver reproducibility, the mean ICC and RMSE were 0.9860 and 2.82, respectively. For interobserver reproducibility, the mean ICC and RMSE were 0.9755 and 4.13 , respectively.

\section{Statistical Analysis}

Statistical analyses were performed using Microsoft Excel 2007 for Windows with the add-in software Statcel 2 (OMS Ltd.). The data were analyzed using the nonparametric Mann-Whitney U-test and Spearman's rank correlation coefficient, where indicated. A $p$ value $<0.05$ was considered statistically significant. Correlation analyses were performed using the Spearman rank-correlation coefficient. The ICC was calculated using SPSS for Windows (version 21.0, IBM).

\section{Results}

\section{Motion Around the Anatomical Coordinate System in the Control Group}

SI joint motion during trunk flexion-extension was minute in the control group (Fig. 4 and Table 1). The mean rotation angles during trunk flexion were $0.07^{\circ}$ around the $\mathrm{x}$ axis, $-0.02^{\circ}$ around the $\mathrm{y}$ axis, and $0.16^{\circ}$ around the $\mathrm{z}$ axis. The mean rotation angles during trunk extension were $0.38^{\circ}$ around the $\mathrm{x}$ axis, $-0.08^{\circ}$ around the $\mathrm{y}$ axis, and $0.08^{\circ}$ around the $\mathrm{z}$ axis. During trunk flexion-extension, the largest amount of motion occurred around the $\mathrm{x}$ axis.

\section{Motion Around the Anatomical Coordinate System in the DLSD Group}

SI joint motion during trunk flexion-extension was also minute, but there was great individual difference in 
TABLE 1. SI joint motion in the control group

\begin{tabular}{|c|c|c|c|}
\hline \multirow[b]{2}{*}{ Parameter } & \multirow{2}{*}{$\begin{array}{l}\text { No. of } \\
\text { Sides }\end{array}$} & \multicolumn{2}{|c|}{ Mean \pm SD (range) } \\
\hline & & Trunk Flexion & Trunk Extension \\
\hline \multicolumn{4}{|l|}{ Rotation } \\
\hline$x$ axis in ${ }^{\circ}$ & 26 & $0.07 \pm 0.36(-0.38$ to 0.81$)$ & $0.38 \pm 0.35(-0.19$ to 1.30$)$ \\
\hline$y$ axis in ${ }^{\circ}$ & 26 & $-0.02 \pm 0.08(-0.23$ to 0.16$)$ & $-0.08 \pm 0.19(-0.54$ to 0.34$)$ \\
\hline$z$ axis in ${ }^{\circ}$ & 26 & $0.16 \pm 0.11(-0.07$ to 0.31$)$ & $0.08 \pm 0.20(-0.37$ to 0.51$)$ \\
\hline \multicolumn{4}{|l|}{ Translation } \\
\hline $\mathrm{x}$ axis in $\mathrm{mm}$ & 26 & $-0.13 \pm 0.08(-0.25$ to 0.03$)$ & $0.00 \pm 0.18(-0.45$ to 0.40$)$ \\
\hline$y$ axis in $\mathrm{mm}$ & 26 & $0.10 \pm 0.19(-0.23$ to 0.75$)$ & $-0.56 \pm 0.36(-1.50$ to -0.10$)$ \\
\hline $\mathrm{z}$ axis in $\mathrm{mm}$ & 26 & $0.13 \pm 0.29(-0.28$ to 0.77$)$ & $1.01 \pm 0.45$ (0.31 to 2.21$)$ \\
\hline Rotation around helical axis in ${ }^{\circ}$ & 26 & $0.36 \pm 0.20(0.14$ to 0.84$)$ & $0.52 \pm 0.30(0.12$ to 1.41$)$ \\
\hline
\end{tabular}

TABLE 2. SI joint motion in the DLSD group

\begin{tabular}{|c|c|c|c|}
\hline \multirow[b]{2}{*}{ Parameter } & \multirow{2}{*}{$\begin{array}{l}\text { No. of } \\
\text { Sides }\end{array}$} & \multicolumn{2}{|c|}{ Mean \pm SD (range) } \\
\hline & & Trunk Flexion & Trunk Extension \\
\hline \multicolumn{4}{|l|}{ Rotation } \\
\hline$x$ axis in ${ }^{\circ}$ & 40 & $0.57 \pm 1.31(-2.35$ to 4.23$)$ & $0.68 \pm 1.29(-1.94$ to 3.38$)$ \\
\hline$y$ axis in ${ }^{\circ}$ & 40 & $0.01 \pm 0.44(-1.57$ to 1.03$)$ & $-0.11 \pm 0.36(-1.21$ to 0.74$)$ \\
\hline$z$ axis in ${ }^{\circ}$ & 40 & $0.19 \pm 0.41(-0.57$ to 1.51$)$ & $0.05 \pm 0.45(-1.92$ to 0.88$)$ \\
\hline \multicolumn{4}{|l|}{ Translation } \\
\hline $\mathrm{x}$ axis in $\mathrm{mm}$ & 40 & $-0.13 \pm 0.30(-1.02$ to 0.38$)$ & $0.02 \pm 0.33(-0.88$ to 0.90$)$ \\
\hline y axis in $\mathrm{mm}$ & 40 & $-0.05 \pm 0.72(-1.64$ to 1.92$)$ & $-0.43 \pm 0.73(-2.24$ to 1.14$)$ \\
\hline $\mathrm{z}$ axis in $\mathrm{mm}$ & 40 & $0.42 \pm 1.13(-2.11$ to 4.11$)$ & $0.84 \pm 1.22(-1.56$ to 3.87$)$ \\
\hline Rotation around helical axis in ${ }^{\circ}$ & 40 & $1.10 \pm 1.02(0.07$ to 4.74$)$ & $1.30 \pm 1.03(0.17$ to 3.40$)$ \\
\hline
\end{tabular}

the DLSD group (Fig. 4 and Table 2). The mean rotation angles during trunk flexion were $0.57^{\circ}$ around the $\mathrm{x}$ axis, $0.01^{\circ}$ around the $\mathrm{y}$ axis, and $0.19^{\circ}$ around the $\mathrm{z}$ axis. The mean rotation angles during trunk extension were $0.68^{\circ}$ around the $\mathrm{x}$ axis, $-0.11^{\circ}$ around the $\mathrm{y}$ axis, and $0.05^{\circ}$ around the $\mathrm{z}$ axis. During trunk flexion-extension, the largest amount of motion occurred around the $\mathrm{x}$ axis.

\section{Helical Axis and Motion Around the Axis}

Although the helical axes of SI joint motion during both trunk extension and flexion were scattered among the participants, the axes tended to run posteriorly to the sacrum (Fig. 5). Motion around the helical axis was $0.36^{\circ}$ during trunk flexion and $0.52^{\circ}$ during trunk extension in the control group, $0.88^{\circ}$ during trunk flexion and $0.87^{\circ}$ during trunk extension in men in the DLSD group, and $1.42^{\circ}$ during trunk flexion and $1.62^{\circ}$ during trunk extension in women in the DLSD group (Fig. 6 and Table 3). Members of the DLSD group had significantly more motion and greater individual difference than did those in the control group. Within the DLSD group, women had significantly more motion than men during trunk extension.

\section{Correlation Between Joint Motion and the Cross-Sectional Area of the Trunk Muscles}

SI joint motion was significantly negatively correlated with the cross-sectional area of the trunk muscles during both trunk flexion and extension (during flexion: $\mathrm{R}=-0.38$, $\mathrm{p}=0.00$; during extension: $\mathrm{R}=-0.53, \mathrm{p}=0.02$; Fig. 7).

\section{Discussion}

SI joint mobility continues to be a major topic of debate. Many researchers have attempted to elucidate the kine-

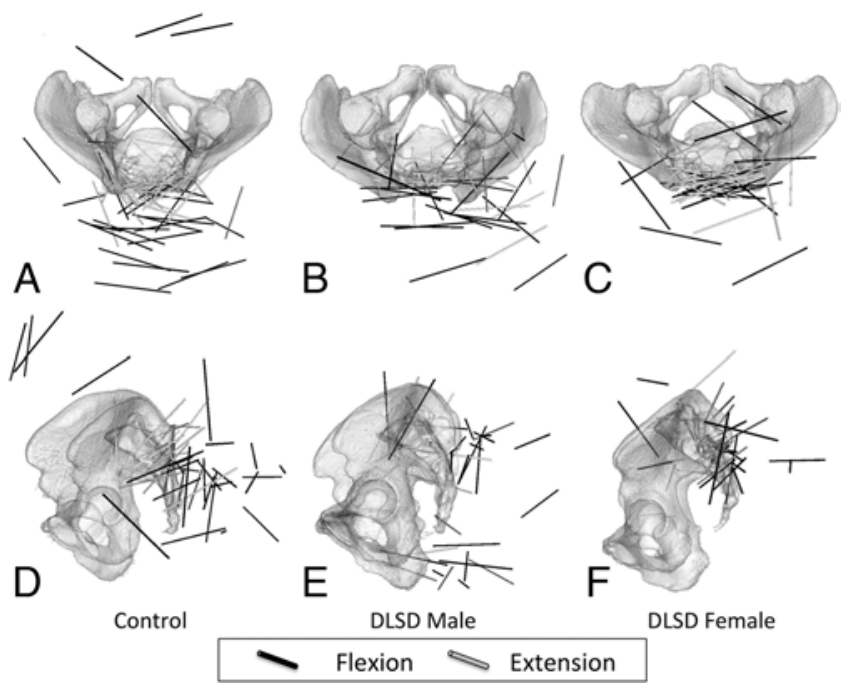

FIG. 5. Relative motion of the sacrum to the ilium described with helical axis of rotation. A-C: Craniocaudal views. D-F: lateral views. 


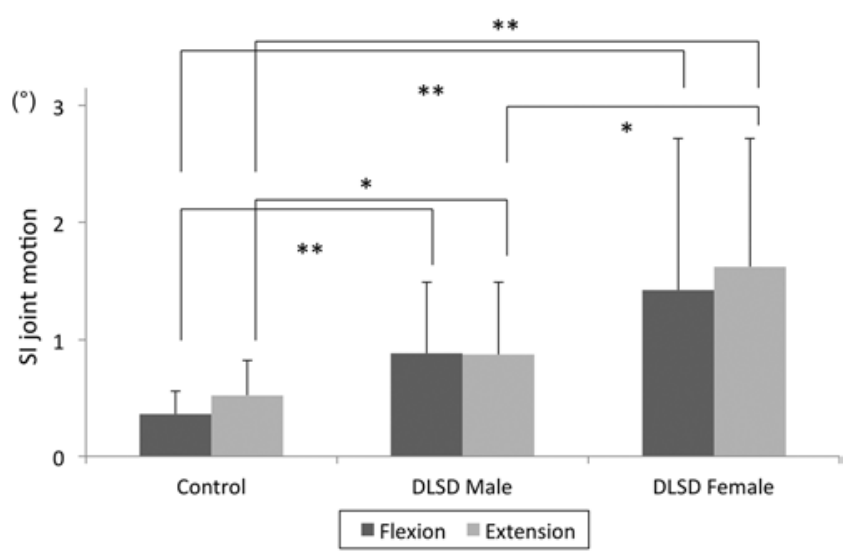

FIG. 6. Motion of the sacral bone relative to the iliac bone (SI joint motion), described with the angle of rotation around helical axis. Data represent mean $\pm S D$. ${ }^{*} p<0.05 ;{ }^{* *} p<0.01$.

matics of the joint, but only a few have been able to accurately measure the joint's in vivo motion., ${ }^{4,13,17-19,25}$ In all of those studies, rotation mainly occurred around the SI joint surface (the $\mathrm{x}$ axis), and translation was minute. Sturesson and colleagues measured SI joint motion with various positions, using RSA. ${ }^{17-19}$ In all test situations, about $90 \%$ of total motion occurs around the $\mathrm{x}$ axis..$^{17} \mathrm{~A}$ maximum rotation around the $\mathrm{x}$ axis of $3.9^{\circ}$ has been measured, and the translation along a single axis never exceeded $2 \mathrm{~mm}$. When study participants changed from a supine to a prone position with the same or contralateral leg hyperextended, maximum motion occurred. Although RSA is a well-established and very accurate method, its accuracy relies on the distance between bone markers and their distribution along all 3 axes. For the SI joint, the markers could be placed only on the dorsal side of the sacrum and ilium in previous studies. They were placed close to the joint surface and tended to align collinearly or in the same plane. Because this is not necessarily the optimal 3D distribution, Cibulka questioned the usefulness of RSA for measuring SI joint motion. ${ }^{1}$ Therefore, we used the voxel-based registration method in our study to measure SI joint motion. This is a very accurate method for measuring joint kinematics, as previously reported, ${ }^{5-8,10-12,15}$ and it is thought to be more suitable than RSA for measuring SI joint motion because it can fully use the morphological information of the entire bone for tracking motion, which is not the case when only tracking makers are used, as in RSA. In using voxel-based registration, we found that during trunk flexion-extension, maximum rotation occurred around the $\mathrm{x}$ axis, and translation along a single axis never exceeded $2 \mathrm{~mm}$, a finding that is almost the same as that in previous studies that used RSA.

It is commonly assumed that the helical axis of rotation for SI joint motion would pass transversely through the S-2 vertebra such that the sacrum performs a nutation in the sagittal plane about this axis. ${ }^{13}$ Jacob et al..$^{13}$ measured in vivo SI joint motion during trunk flexion-extension in 24 healthy volunteers using a bicamera and $\mathrm{K}$ wires and found that the average value for total rotation around a helical axis was low $\left(1.7^{\circ}\right)$. They also reported that the axis passes transversely near the posterior corner of the superior endplate of the sacrum. In our study, the motion during trunk flexion-extension was also minute and the axes tended to run posteriorly to the sacrum with considerable variation. This is partly because the rotational motion around the helical axis might be too small relative to the translational motion.

It has been well documented that lumbosacral fusion is associated with high rates of pseudarthrosis, despite the use of various sacral fixation techniques. ${ }^{14}$ Tsuchiya et al. reported a good union rate and good clinical results for lumbosacral instrumented fusion augmented with iliac screws..$^{20}$ A recent cadaver study also showed that sacral screw strain is reduced by supplemental iliac screws for instrumented long spine fusions. ${ }^{3}$ For the aforementioned reasons, in patients with DLSDs, especially adult spinal deformity, long fusion to the sacrum usually requires additional anchors into the ilium. There are many techniques available for anchoring; the 2 most commonly used involve iliac screws and S-2 alar iliac screws. Given our results with the helical axis, S-2 alar iliac screws seem to have a biomechanical advantage over iliac screws because S-2 alar iliac screws are placed farther from the helical axis of rotation (or instantaneous axis of rotation) ${ }^{24}$ of SI joint motion than iliac screws. Although the use of anchors is becoming quite common, surgeons must always keep in mind that the SI joint is mobile, and they should be aware of the kinematic properties of the SI joint in patients with DLSDs, including adult spine deformity. Some authors have reported that iliac screw fixation is still associated with a high rate of mechanical failure., ${ }^{920}$ They speculated that the involvement of mobile joints contributed to the failure of these constructs.

TABLE 3. Rotational motion around the helical axis

\begin{tabular}{|c|c|c|c|c|}
\hline \multirow[b]{2}{*}{ Group } & \multirow{2}{*}{$\begin{array}{l}\text { No. of } \\
\text { Sides }\end{array}$} & \multirow{2}{*}{$\begin{array}{c}\text { Mean Age } \\
\text { (yrs) }\end{array}$} & \multicolumn{2}{|c|}{ Mean \pm SD (range) } \\
\hline & & & Trunk Flexion in Degrees & Trunk Extension in Degrees \\
\hline \multicolumn{5}{|c|}{ Control group } \\
\hline Men & 26 & 30 & $0.36 \pm 0.20(0.14$ to 0.84$)$ & $0.52 \pm 0.30(0.12$ to 1.41$)$ \\
\hline \multicolumn{5}{|c|}{ DLSD group } \\
\hline Total & 40 & 63 & $1.10 \pm 1.02(0.07$ to 4.74$)$ & $1.30 \pm 1.03(0.17$ to 3.40$)$ \\
\hline Male & 20 & $60^{*}$ & $0.88 \pm 0.60$ (0.07 to 2.38$)$ & $0.87 \pm 0.61(0.17$ to 2.50$)$ \\
\hline Female & 20 & $66^{*}$ & $1.42 \pm 1.30(0.13$ to 4.74$)$ & $1.62 \pm 1.10(0.36$ to 3.40$)$ \\
\hline
\end{tabular}

* The difference in age between male and female patients was not significant. 


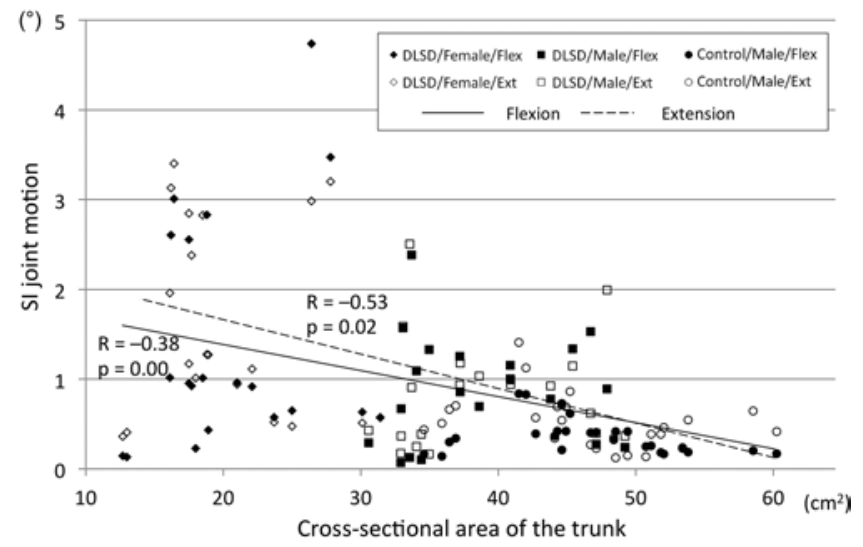

FIG. 7. SI joint motion was significantly negatively correlated with the cross-sectional area of the trunk muscles during both flexion (Flex) and extension (Ext) of the trunk.

To our knowledge, no prior studies have analyzed the kinematic differences of the SI joint with regard to age, sex, or disease state. . $^{13,17,22}$ Our findings clarified that during trunk flexion-extension in patients with DLSDs, including adult spine deformity, SI joint motion is significantly greater, with greater individual difference, than in healthy volunteers. In particular, women in our DLSD group had significantly more motion than did men in the group. It is generally believed that SI joint mobility is greater in women than in men and gradually decreases with aging. ${ }^{2,23}$ We also found a significant negative correlation between SI joint motion and the cross-sectional area of the trunk muscles. This is thought to be because trunk muscles play important role in stabilizing the SI joint. ${ }^{16,21}$

We have a theory regarding a possible mechanism for the increasing SI joint mobility, with great individual difference, found in our DLSD group (Fig. 8): Most patients restricted their activities of daily living because of aging and their spine disorder. Accordingly, their trunk muscles and the range of motion of their entire lumbar spine gradually decreased. This loss of trunk muscle strength and decreasing lumbar spine range of motion might have induced an increase in shear stress on the SI joint, subsequently leading to unstable SI joints in some patients. In other patients, however, osteoarthritis predominantly occurred in the SI joint, resulting in reduced SI joint mobility mainly due to increased joint-surface friction. In addition, SI joint mobility in the DLSD group might have been caused by a complex interaction of surrounding muscles, ligaments, and osteoarthritis of the SI joints. ${ }^{16,21-23}$ It is quite difficult to identify a single factor that is responsible for SI joint mobility.

Our study had several limitations. First, because it was a kinematic study, it could not elucidate the etiology of SI joint pain and/or disorders. Second, to avoid the risks that radiation presents for healthy, fertile women, we did not include women in the control group. Third, the motion measured in our study might have been underestimated in comparison with actual movement because we could not measure motion with the spine under load. Despite these limitations, we believe our findings are important for spine surgeons in clinical practice because of the recent increase

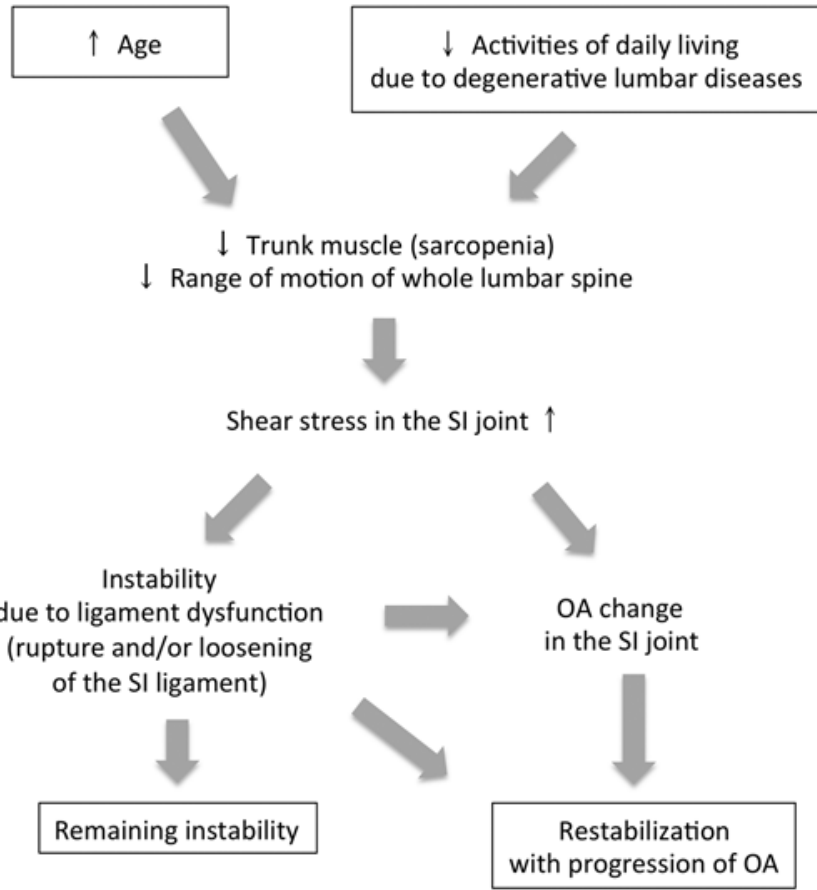

FIG. 8. A possible mechanism for increase in SI joint mobility in degenerative lumbar spine diseases. $\mathrm{OA}=$ osteoarthritis.

of spinopelvic fusion for the treatment of DLSDs. Our study represents a step toward a better understanding of kinematic change of the SI joint in patients with DLSDs.

\section{Conclusions}

We elucidated the mobility and kinematic characteristics of the SI joint during trunk flexion-extension in patients with DLSDs compared with healthy volunteers for the first time. SI joint motion during trunk flexion-extension mainly occurred around the joint surface (the $\mathrm{x}$ axis). Joint motion in patients with DLSDs was significantly greater, with greater individual difference, than in healthy volunteers. Among patients with DLSDs, women had significantly more motion than men during trunk extension. SI joint motion was significantly negatively correlated with the cross-sectional area of the trunk muscles during both trunk flexion and extension. In view of our findings and the increased use of augmentation in lumbosacral fusion, it is imperative that surgeons have accurate knowledge of the kinematic properties of the SI joint, especially in patients with DLSDs, and that surgeons always keep in mind that the SI joint is mobile.

\section{Acknowledgments}

We thank Ryoji Nakao for assisting with software programming and Shinichiro Hirose for help with CT imaging. Medical editor Katharine O'Moore-Klopf, ELS (East Setauket, NY), provided professional English-language editing of this article.

\section{References}

1. Cibulka MT: Re: a radiostereometric analysis of the movements of the sacroiliac joints in the reciprocal straddle position. Spine (Phila Pa 1976) 26:1404-1405, 2001 (Letter) 
2. Cohen SP: Sacroiliac joint pain: a comprehensive review of anatomy, diagnosis, and treatment. Anesth Analg 101:14401453,2005

3. Cunningham BW, Sefter JC, Hu N, Kim SW, Bridwell KH, McAfee PC: Biomechanical comparison of iliac screws versus interbody femoral ring allograft on lumbosacral kinematics and sacral screw strain. Spine (Phila Pa 1976) 35:E198E205, 2010

4. Egund N, Olsson TH, Schmid H, Selvik G: Movements in the sacroiliac joints demonstrated with roentgen stereophotogrammetry. Acta Radiol Diagn (Stockh) 19:833-846, 1978

5. Fujii R, Sakaura H, Mukai Y, Hosono N, Ishii T, Iwasaki M, et al: Kinematics of the lumbar spine in trunk rotation: in vivo three-dimensional analysis using magnetic resonance imaging. Eur Spine J 16:1867-1874, 2007

6. Fujimori T, Iwasaki M, Nagamoto Y, Ishii T, Sakaura H, Kashii M, et al: Three-dimensional measurement of growth of ossification of the posterior longitudinal ligament. J Neurosurg Spine 16:289-295, 2012

7. Fujimori T, Iwasaki M, Nagamoto Y, Kashii M, Ishii T, Sakaura H, et al: Three-dimensional measurement of intervertebral range of motion in ossification of the posterior longitudinal ligament: are there mobile segments in the continuous type? J Neurosurg Spine 17:74-81, 2012

8. Fujimori T, Iwasaki M, Nagamoto Y, Matsuo Y, Ishii T, Sugiura T, et al: Kinematics of the thoracic spine in trunk lateral bending: in vivo three-dimensional analysis. Spine J 14:1991-1999, 2014

9. Gitelman A, Joseph SA Jr, Carrion W, Stephen M: Results and morbidity in a consecutive series of patients undergoing spinal fusion with iliac screws for neuromuscular scoliosis. Orthopedics 31:1-5, 2008

10. Ishii T, Mukai Y, Hosono N, Sakaura H, Fujii R, Nakajima $\mathrm{Y}$, et al: Kinematics of the cervical spine in lateral bending: in vivo three-dimensional analysis. Spine (Phila Pa 1976) 31:155-160, 2006

11. Ishii T, Mukai Y, Hosono N, Sakaura H, Fujii R, Nakajima $\mathrm{Y}$, et al: Kinematics of the subaxial cervical spine in rotation in vivo three-dimensional analysis. Spine (Phila Pa 1976) 29:2826-2831, 2004

12. Ishii T, Mukai Y, Hosono N, Sakaura H, Nakajima Y, Sato $Y$, et al: Kinematics of the upper cervical spine in rotation: in vivo three-dimensional analysis. Spine (Phila Pa 1976) 29:E139-E144, 2004

13. Jacob HA, Kissling RO: The mobility of the sacroiliac joints in healthy volunteers between 20 and 50 years of age. Clin Biomech (Bristol, Avon) 10:352-361, 1995

14. Lee CS, Chung SS, Choi SW, Yu JW, Sohn MS: Critical length of fusion requiring additional fixation to prevent nonunion of the lumbosacral junction. Spine (Phila Pa 1976) 35:E206-E211, 2010

15. Nagamoto $Y$, Ishii $T$, Sakaura $H$, Iwasaki M, Moritomo H, Kashii M, et al: In vivo three-dimensional kinematics of the cervical spine during head rotation in patients with cervical spondylosis. Spine (Phila Pa 1976) 36:778-783, 2011

16. Richardson CA, Snijders CJ, Hides JA, Damen L, Pas MS, Storm J: The relation between the transversus abdominis muscles, sacroiliac joint mechanics, and low back pain. Spine (Phila Pa 1976) 27:399-405, 2002

17. Sturesson B, Selvik G, Udén A: Movements of the sacroiliac joints. A roentgen stereophotogrammetric analysis. Spine (Phila Pa 1976) 14:162-165, 1989

18. Sturesson B, Uden A, Vleeming A: A radiostereometric analysis of movements of the sacroiliac joints during the standing hip flexion test. Spine (Phila Pa 1976) 25:364-368, 2000

19. Sturesson B, Uden A, Vleeming A: A radiostereometric analysis of the movements of the sacroiliac joints in the recipro- cal straddle position. Spine (Phila Pa 1976) 25:214-217, 2000

20. Tsuchiya K, Bridwell KH, Kuklo TR, Lenke LG, Baldus C: Minimum 5-year analysis of L5-S1 fusion using sacropelvic fixation (bilateral S1 and iliac screws) for spinal deformity. Spine (Phila Pa 1976) 31:303-308, 2006

21. van Wingerden JP, Vleeming A, Buyruk HM, Raissadat K: Stabilization of the sacroiliac joint in vivo: verification of muscular contribution to force closure of the pelvis. Eur Spine J 13:199-205, 2004

22. Vleeming A, Van Wingerden JP, Dijkstra PF, Stoeckart R, Snijders CJ, Stijnen T: Mobility in the sacroiliac joints in the elderly: a kinematic and radiological study. Clin Biomech (Bristol, Avon) 7:170-176, 1992

23. Vleeming A, Volkers ACW, Snijders CJ, Stoeckart R: Relation between form and function in the sacroiliac joint. Part II Biomechanical aspects. Spine (Phila Pa 1976) 15:133-136, 1990

24. White AA III, Panjabi MM: Clinical Biomechanics of the Spine, ed 2. Philadelphia: Lippincott Williams \& Wilkins, 1990

25. Wilke HJ, Fischer K, Jeanneret B, Claes L, Magerl F: [In vivo measurement of 3-dimensional movement of the iliosacral joint.] Z Orthop Ihre Grenzgeb 135:550-556, 1997 (Ger)

\section{Author Contributions}

Conception and design: Nagamoto, Iwasaki. Acquisition of data: Nagamoto, Sugiura, Fujimori, Matsuo. Analysis and interpretation of data: Nagamoto, Fujimori. Drafting the article: Nagamoto. Critically revising the article: Iwasaki, Sakaura, Fujimori. Reviewed submitted version of manuscript: Iwasaki, Sakaura, Sugiura, Fujimori, Matsuo, Kashii, Murase, Yoshikawa, Sugamoto. Statistical analysis: Nagamoto. Administrative/technical/ material support: Murase, Yoshikawa, Sugamoto. Study supervision: Iwasaki, Sakaura, Sugamoto.

\section{Supplemental Information \\ Previous Presentation}

Some study findings were presented in the podium session at the 39th annual meeting of the Cervical Spine Research Society (Phoenix, AZ, December 8-10, 2011).

\section{Videos}

Video 1, Media Player. http://mfile.akamai.com/21490/wmv/ digitalwbc.download.akamai.com/21492/wm.digitalsource-naregional/spine14-590_video_1.asx.

Video 1, Quicktime. http://mfile.akamai.com/21488/mov/ digitalwbc.download.akamai.com/21492/qt.digitalsource-global/ spine14-590_video_1.mov.

Video 2, Media Player. http://mfile.akamai.com/21490/wmv/ digitalwbc.download.akamai.com/21492/wm.digitalsource-naregional/spine14-590_video_2.asx.

Video 2, Quicktime. http://mfile.akamai.com/21488/mov/ digitalwbc.download.akamai.com/21492/qt.digitalsource-global/ spine14-590_video_2.mov.

\section{Current Affiliation}

Dr. Nagamoto: Department of Orthopaedics, Osaka National Hospital, Osaka, Japan.

\section{Correspondence}

Yukitaka Nagamoto, Department of Orthopaedic Surgery, Osaka National Hospital, 2-1-14 Hoenzaka, Osaka 540-0006, Japan. email:7gam0to@gmail.com. 